\title{
Effect of Core Stability Exercises on Hand Functions in Children With Hemiplegic Cerebral Palsy
}

\author{
Hanaa Mohsen Abd-Elfattah, $\mathrm{PhD}^{1}$, Sobhy Mahmoud Aly, PhD ${ }^{2}$
}

\begin{abstract}
${ }^{1}$ Department of Physical Therapy for Pediatrics and Pediatric Surgery, Faculty of Physical Therapy, Badr University, Cairo; ${ }^{2}$ Department of Biomechanics, Faculty of Physical Therapy, Cairo University, Cairo, Egypt
\end{abstract}

Objective To investigate the effectiveness of core stability exercises on hand functions in children with hemiplegic cerebral palsy.

Methods Fifty-two children with hemiplegic cerebral palsy ranging in age from 6 years to 8 years were enrolled in this study. They were randomly assigned to two (control and study) groups. The control group received the selected physiotherapy exercises, and the study group received the same selected physiotherapy exercise program and core stability exercises. Time motor performance, gross manual dexterity, and upper extremity skills assessed using the Jebsen Taylor Hand Function Test, Box and Block Test, and Quality Upper Extremity Skill Test, respectively, were measured before and after 12 weeks of the treatment program.

Results There were significant improvements in both groups by comparing the mean values of all measured variables before and after treatment $(\mathrm{p}<0.05)$. There were significant differences between the control and study groups with respect to all measured variables when comparing the post-treatment outcomes $(\mathrm{p}<0.05)$.

Conclusion This study suggests that core stability exercises can be an effective intervention that may improve hand functions in children with hemiplegic cerebral palsy.

Keywords Hemiplegia, Cerebral palsy, Children, Hand, Core stability

\section{INTRODUCTION}

Children with hemiplegic cerebral palsy (CP) have an upper limb impairment, which can influence the capacity to perform and participate in activities of daily living (ADLs). This impairment results from spasticity, im- paired sensation, and reduced strength. Consequently, the functional ability of the upper limb is often compromised [1]. Lesions in the sensorimotor cortex and corticospinal tract result in unilateral prehensile dysfunction. These children regularly have unpredictable patterns of prehension, weakness, spasticity, incomplete fraction-

Received June 23, 2020; Revised July 31, 2020; Accepted September 28, 2020; Published online February 9, 2021

Corresponding author: Hanaa Mohsen Abd-Elfattah

Department of Physical Therapy for Pediatrics and Pediatric Surgery, Faculty of Physical Therapy, Badr University, Cairo, Egypt. Tel: $+20-1009106127$, Fax:+20-00227238732, E-mail: Hanaa753@gmail.com

ORCID: Hanaa Mohsen Abd-Elfattah (https://orcid.org/0000-0003-0018-8878); Sobhy Mahmoud Aly (https://orcid.org/0000-0003-1666-2802).

(c) This is an open-access article distributed under the terms of the Creative Commons Attribution Non-Commercial License (http://creativecommons.org/ licenses/by-nc/4.0) which permits unrestricted noncommercial use, distribution, and reproduction in any medium, provided the original work is properly cited. Copyright (C) 2021 by Korean Academy of Rehabilitation Medicine 
ation of fingers, and sensory disturbance. Children with hemiplegic $\mathrm{CP}$ have impaired fingertip force control and timing during object manipulation [2].

The manipulative actions and fine motor skills in typically developing children improve rapidly during the first years of life, with subsequent refinement occurring throughout childhood [3].

Children with hemiplegia may have debilitating symptoms affecting play, education, and self-care. In addition, children with hemiplegic CP barely use the affected hand to perform unimanual activities. The affected hand is typically used when bimanual task performance is required [4]. There are several traditional approaches, such as the use of modalities, splinting, casting, passive stretching, and promoting posture and mobility of the upper limbs of children with hemiplegic $\mathrm{CP}$, with the goal of decreasing muscle tone and spasticity, enhancing the range of movement of the affected limb, and improving the functional use of the limb [5].

"Core stability" describes the ability to control the position and movement of the central portion of the body. Core exercise is directed to the deep muscles inside the abdomen that connect with the spine, pelvis, and shoulders to maintain good posture, thus providing a foundation for extremity movement. Spinal stability is important for movement development and depends on the core muscles to achieve adequate strength, power, and endur- ance [6]. Components of core stability include strength, endurance, balance, and related back, abdominal, and pelvic muscle activities $[7,8]$.

The effectiveness of postural control and body center on fine manual dexterity is a common assumption. The neuromuscular system is closely linked to almost all centers of the central nervous system that regulate muscle tension (tone), process sensory information, and organize motor responses. The pyramidal system transmits "action plans" originated from the cortical motor areas and controlled the complexity of voluntary movements and versatile maneuvers of upper extremities [9].

It is essential to incorporate methods that can maximize the use of the affected extremity. Thus, the aim of this study was to investigate the influence of core stability exercises on hand functions in children with hemiplegic CP.

\section{MATERIALS AND METHODS}

\section{Study design}

A randomized, single-blind, controlled clinical trial was conducted at the Faculty of Physical Therapy outpatient clinic, Badr University in Cairo.

\section{Participants}

Sixty children with hemiplegic CP were recruited for

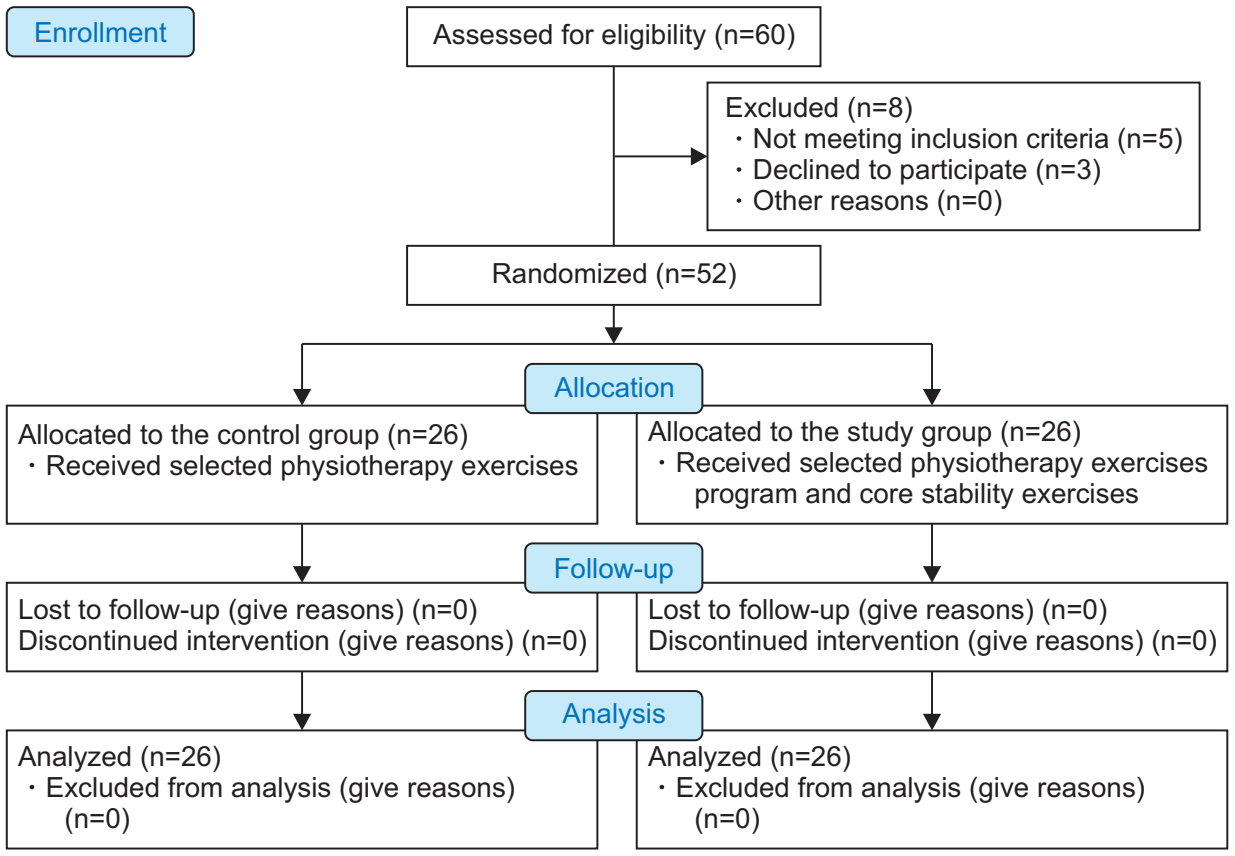

Fig. 1. Participant's flow diagram. 
this study; five children did not meet the inclusion criteria, and the parents of three children refused to participate in the study. Following the baseline measurements, children were assigned randomly into two equivalent groups using closed envelopes. The therapist prepared sealed envelopes, which contained a piece of paper indicating whether each child was allocated to the control group or the study group. The experimental design is shown in the flow diagram in Fig. 1.

Fifty-two children with hemiplegic CP (35 boys, 17 girls) participated in this randomized controlled study. Children were included in this study based on the following criteria: age ranging from 6 years to 8 years, diagnosed with hemiplegic $\mathrm{CP}$ verified by magnetic resonance images obtained from medical documents, and mild spasticity of the upper limb (Modified Ashworth Scale grade 1 to $1+$ ) [10]. The children were categorized as level I to II, according to the Gross Motor Function Classification System [11]. Also, these children were cognitively competent and able to understand and follow instructions. Some children were excluded from this study in the case of fixed contracture or deformities in the spine or extremities, visual or respiratory disorders, a history of orthopedic surgery on the affected limb, dorsal rhizotomy, botulinum toxin injection in the upper limb within the last 6 months, or planning to have one during the study period. Prior to data collection, the purposes, procedures, and benefits were fully explained to the parents of the participating children. This study was conducted in accordance with declaration of Helsinki guidelines for studies involving humans. This study was approved by the Ethics Review Committee of the Faculty of Physical Therapy, Cairo University (No. P.T.REC/012/002582). Prior to data collection, the purpose, procedures and benefits were fully explained to the parents of the participating children and the consent form was obtained.

\section{Outcome measures}

All procedures were performed at baseline (pre-treatment) and the end of 3 successive months of treatment (post-treatment) in a warm lighted and quiet room.

\section{Jebsen Taylor Hand Function Test}

The child sat in front of a table to conduct the Jebsen Taylor Hand Function Test (JTHFT), where the evaluation was carried out [12]. The test includes seven items.
All items except writing were tested: writing depends on the level of education and hand dominance and has low reliability $[13,14]$. Each trial was separated by 60 seconds to 90 seconds of break to minimize any potential fatigue. It took a maximum of 2 minutes (120 seconds) for each item to be completed. The shorter the time taken for the JTHFT, the more efficient the performance is [15].

\section{Box and Block Test (BBT)}

The child was sitting on an adjusted chair in front of a two-compartment box placed on a table containing 150 blocks. The child should place his/her hands on the sides of the box as preparation before the test begins. Following the instructions, the child was given a 15 -second trial. The test includes grasping, moving, and releasing wooden blocks from one side to the other. During the test, the child should pick up only one block and transport it over the partition before he/she can place the block in the other compartment. The score was recorded for 1 minute as the number of blocks passed over the wooden partition [16].

\section{Quality Upper Extremity Skill Test}

The Quality Upper Extremity Skill Test (QUEST) was developed to specifically overcome the limitations of currently available measures of hand function. This measurement evaluates the quality of upper extremity skill function through 33 activity items of 4 domains: dissociated movement consists of 19 items, grasp consists of 6 items, weight-bearing consists of 5 items, and protective extension consists of 3 items.

It is designed for children who exhibit neuromotor impairment with spasticity and validated for children aged 18 months to 8 years. The test takes $30-40$ minutes, and its scores range from 0 to 100 [17].

\section{Intervention}

All participants received the same selected physiotherapy program for the affected upper extremity, which consists of facilitation of postural mechanism; proprioceptive training, including weight-bearing activities for the upper and lower limbs; strengthening exercises for the back, abdominal muscles, ankle dorsiflexors, knee (flexors and extensors), and hip (flexors, extensors, abductors, internal and external rotators); standing exercises (standing holding on, standing alone with arms 
free, standing holding on and asking the child to lift one foot, standing on one leg, standing on balance board); gait training in different directions at a different speed; and up and downstairs and jumping in place and broad jumping. This program was given for 1 hour with a rest period of 2 minutes between each group of exercises, 3 days a week for 12 weeks. The study group received additional core stability exercises, which consist of three levels. Each level took 4 weeks. The difficulty of each level varies in proprioception, balance, and stability as it started from exercising on a stable surface "mat" and ended with unstable surface "physioball". The first simple level involves supine abdominal draw ( 3 sets per 20 repetitions), abdominal draw-in with a double knee to chest (3 sets $/ 20$ repetitions), and supine twist (3 sets per 20 repetitions). The second medium level involves pelvic bridging (3 sets per 3-5 repetitions) and twists with a medicine ball ( 3 sets per 10-20 repetitions). The third difficult level involves bridging with head-on physioball holding this position for 3-5 seconds, then slowly relaxing (3 sets per 10-20 repetitions), and prone bridging ( 3 sets per $3-5$ repetitions). There was a 30 -second rest between sets [18].

All participants were cooperative during treatment sessions, and the adherence rate was approximately $97 \%$.

\section{Sample size}

The pre-study sample size calculation was performed based on a pilot study using G*Power statistical software (version 3.1.9.2; Franz Faul, University of Kiel, Germany) (F tests-MANOVA: repeated measures, within-between interaction measurements, $\alpha=0.05, \beta=0.2$, and large effect size) and revealed that $\mathrm{n}=52$ was the appropriate sample size for this study.

\section{Data analysis}

A t-test was used to analyze subject characteristics between groups. Sex and affected side distribution were compared between groups using the chi-square test. The Shapiro-Wilk test was used to check the normal distribution of data, and Levene's test for homogeneity was conducted to test the homogeneity between groups. Within and between groups, effects on subtests of JTHFT, QUEST, and BBT were investigated by mixed MANOVA. Multiple post-hoc tests were conducted using Bonferroni correction. A $\mathrm{p}<0.05$ was the level of significance. SPSS software version 25 (IBM SPSS, Armonk, NY, USA) was used for all statistical tests.

\section{RESULTS}

\section{Subject characteristics}

There was no significant difference between both groups in the subject characteristics $(\mathrm{p}<0.05)$ (Table 1$)$.

\section{Effect of treatment on subtests of JTHFT, QUEST, and BBT}

There was a significant interaction between treatment and time (Wilks' $\lambda=0.02 ; \mathrm{F}_{(11,40)}=159.86, \mathrm{p}=0.001, \eta^{2}=0.97$ ). There was a significant main effect of time (Wilks' $\lambda=0.003$; $\left.\mathrm{F}_{(11,40)}=1234.97, \mathrm{p}=0.001, \eta^{2}=0.99\right)$. There was a significant main effect of treatment (Wilks' $\lambda=0.02 ; F_{(11,40)}=138.09$, $\left.\mathrm{p}=0.001, \eta^{2}=0.97\right)$.

\section{Within-group comparison}

After treatment, there were significant improvements in the JTHFT subtest time and QUEST and BBT subtest scores in both groups compared to the pre-treatment results. There was a significant increase in the score of subtests of QUEST and BBT in the control and study groups post-treatment compared with the pre-treatment score $(\mathrm{p}<0.001)$ (Table 2).

\section{Between-group comparison}

Before treatment, there was no significant difference between groups in all parameters $(p>0.05)$. After treatment, there was a significant decrease in the time of subtests of JTHFT of the study group compared with that

Table 1. Basic characteristics of participants

\begin{tabular}{lrrr}
\hline & Control group & Study group & p-value \\
\hline Age (yr) & $6.89 \pm 0.75$ & $7.00 \pm 0.67$ & $0.60^{\text {a) }}$ \\
Weight $(\mathrm{kg})$ & $25.84 \pm 1.07$ & $26.15 \pm 1.63$ & $0.42^{\text {a) }}$ \\
Height $(\mathrm{cm})$ & $120.40 \pm 8.66$ & $119.46 \pm 9.46$ & $0.71^{\text {a) }}$ \\
Gender & & & $0.76^{\text {b) }}$ \\
$\quad$ Girl & $9(34.61)$ & $8(30.76)$ & \\
Boy & $17(65.38)$ & $18(69.23)$ & \\
Affected hand & & & $0.74^{\text {b) }}$ \\
Right & $19(73.07)$ & $20(76.92)$ & \\
Left & $7(26.92)$ & $6(23.07)$ & \\
\hline
\end{tabular}

Values are presented as mean \pm standard deviation or number (\%).

${ }^{a)}$ Using a t-test, ${ }^{\text {b) }}$ chi-square test. 
Table 2. Subtests of JTHFT, subtests of QUEST, and Box and Block Test pre- and post-treatment of control and study groups

\begin{tabular}{|c|c|c|c|c|c|c|c|c|}
\hline & \multicolumn{3}{|c|}{ Pre-treatment } & \multicolumn{3}{|c|}{ Post-treatment } & \multicolumn{2}{|c|}{$\begin{array}{c}\text { p-value }^{\text {b) }} \\
\text { (pre vs. post) }\end{array}$} \\
\hline & $\begin{array}{l}\text { Control } \\
\text { group }\end{array}$ & $\begin{array}{l}\text { Study } \\
\text { group }\end{array}$ & p-value ${ }^{\text {a) }}$ & $\begin{array}{l}\text { Control } \\
\text { group }\end{array}$ & $\begin{array}{l}\text { Study } \\
\text { group }\end{array}$ & p-value ${ }^{\text {a) }}$ & $\begin{array}{l}\text { Control } \\
\text { group }\end{array}$ & $\begin{array}{l}\text { Study } \\
\text { group }\end{array}$ \\
\hline \multicolumn{9}{|l|}{ Subtests of JTHFT (s) } \\
\hline Turning cards over & $15.28 \pm 1.18$ & $15.51 \pm 1.96$ & 0.61 & $12.18 \pm 1.46$ & $9.51 \pm 1.81$ & 0.001 & 0.001 & 0.001 \\
\hline Picking up small object & $22.36 \pm 1.24$ & $21.81 \pm 1.77$ & 0.19 & $18.69 \pm 1.11$ & $11.44 \pm 1.59$ & 0.001 & 0.001 & 0.001 \\
\hline Simulated eating & $33.07 \pm 2.28$ & $33.76 \pm 1.88$ & 0.24 & $27.88 \pm 2.89$ & $21.47 \pm 3.54$ & 0.001 & 0.001 & 0.001 \\
\hline Stacking checker & $16.73 \pm 1.06$ & $16.32 \pm 1.19$ & 0.20 & $13.49 \pm 1.91$ & $9.25 \pm 1.45$ & 0.001 & 0.001 & 0.001 \\
\hline Moving light cans & $8.40 \pm 0.74$ & $8.57 \pm 0.85$ & 0.44 & $5.98 \pm 1.06$ & $3.79 \pm 0.94$ & 0.001 & 0.001 & 0.001 \\
\hline Moving heavy cans & $9.21 \pm 0.76$ & $9.09 \pm 0.83$ & 0.59 & $6.23 \pm 0.66$ & $4.27 \pm 0.88$ & 0.001 & 0.001 & 0.001 \\
\hline \multicolumn{9}{|l|}{ Subtests of QUEST } \\
\hline Dissociated movement & $75.89 \pm 1.16$ & $75.65 \pm 1.82$ & 0.56 & $84.41 \pm 1.82$ & $87.21 \pm 1.33$ & 0.001 & 0.001 & 0.001 \\
\hline Grasp & $70.78 \pm 1.09$ & $71.00 \pm 1.99$ & 0.76 & $80.52 \pm 1.69$ & $84.11 \pm 3.72$ & 0.001 & 0.001 & 0.001 \\
\hline Weight bearing & $80.44 \pm 0.79$ & $80.49 \pm 0.83$ & 0.83 & $91.06 \pm 1.61$ & $93.41 \pm 1.96$ & 0.001 & 0.001 & 0.001 \\
\hline Protective extension & $50.94 \pm 2.32$ & $51.58 \pm 1.89$ & 0.28 & $85.37 \pm 3.29$ & $66.04 \pm 2.64$ & 0.001 & 0.001 & 0.001 \\
\hline $\begin{array}{l}\text { Box and Block Test } \\
\text { (blocks/min) }\end{array}$ & $35.34 \pm 1.32$ & $35.77 \pm 1.14$ & 0.22 & $41.84 \pm 0.96$ & $50.34 \pm 1.05$ & 0.001 & 0.001 & 0.001 \\
\hline
\end{tabular}

Values are presented as mean \pm standard deviation.

JTHFT, Jebsen Taylor Hand Function Test; QUEST, Quality Upper Extremity Skill Test.

${ }^{\text {a) }}$ Between-group comparison, ${ }^{\text {b) }}$ within group comparison.

of the control group $(\mathrm{p}<0.001)$ and a significant increase in the score of subtests of QUEST and BBT in the study group compared with that in the control group $(\mathrm{p}<0.001)$ (Table 2).

\section{DISCUSSION}

The current research has been carried out to investigate the effectiveness of core stability exercises on hand function in children with hemiplegic CP.

There was a significant impairment in motor function of the upper extremity performance in children with hemiplegic CP. The upper extremities of children with CP are commonly impaired to reach, grasp, move, release, and manipulate objects, which are crucial for the quality and performance of ADLs [19]. The limited ability in children with hemiplegic $\mathrm{CP}$ to interact with people and the environment restricts involvement and participation. Motor dysfunction in children with CP induces the impairment of physical activity and lack of general experience [20,21].

This study highlights the potential influence of core stability in relation to hand skills in children with hemiple- gic CP.

The results of the current study revealed that there was significant improvement in control and study groups regarding JTHFT, BBT and QUEST compared with the pretreatment results. These findings support that integration of core exercises in hemiplegic patients along with traditional exercises can enhance the upper extremities functions [22].

This comes in accordance with the study that found a significant correlation between the movement of the upper limb and trunk control as the improved upper limb movement was associated with improved trunk control and stability [23].

The study group after the 3 months of treatment showed significant improvement in JTHFT, BBT and QUEST which could have been attributed by the effect of core exercise in improving the upper limbs functions. These findings support that posture maintenance and trunk stability is needed in children with $\mathrm{CP}$ in order to perform hand motions in playing and eating [24].

Physiological activations of the core muscles result in several biomechanical effects allowing efficient lo- 
cal and distal function. Core muscle exercises result in anticipatory postural adjustments, which position the body to withstand balance disturbance created by the kicking, throwing, or running forces [25]. Core stability is a dynamic process in which optimum muscle capacity is required and neuromuscular control that can quickly integrate sensory input and adjust motor responses relative to internal and external input [26]. Moreover, training the core musculature on an unstable surface (e.g., physioball) improves the balance, stability, and proprioceptive capabilities. This gives a consistent feedback about the interactions between the body and the environment and permitting the precision of movement [27].

Significant improvement of hand functions reported in this study may be attributed to the internal and external sensory input which plays a crucial role in motor rehabilitation. Also, it can be attributed to anticipatory postural adjustments that developed with core stability exercises that create the proximal stability for distal mobility.

Core muscles play an important role in the stability as well as mobility of the body parts in preserving balance, improving the upper and lower limb's mobility against gravity; thereby facilitate the functioning of the arms and legs [28-30].

Core exercises improve trunk stability to enhance upper limb efficiency as improving proximal stability will improve distal mobility. Core exercises improved upper limb function in relation to skilled motor behavior and postural sway [31]. This comes in agreement with a previous study, which reported that proximal activation of the core muscles provides either maximum force at the distal end, similar to whip cracking, or provide precision and stability to the distal end. For instance, maximum internal rotation force of the shoulder to rotate the arm is generated by the interactive moment of trunk rotation [32].

On the other hand, the results of this study come in disagreement with another study that reported that the core muscle exercise had no obvious effect on enhancing upper limb function as compared to conventional physical therapy. This difference in results may be due to insufficient duration of exercise. Six weeks of core stability exercises may not be enough to produce significant improvement in muscle strength that appears in comparison between groups and not enough to produce a change in upper limb function, as the rate of gain from exercises may not be evident [33].
This study was limited by the lack of direct measurement of core and hand muscle strength. There was no follow-up of the children to ensure the long-term maintenance of the improvement.

Future studies should investigate the long-term effects of core stability programs for children with CP.

In conclusion, the obtained results demonstrate that core exercises help to improve hand functions in children with hemiplegic CP.

\section{CONFLICT OF INTEREST}

No potential conflict of interest relevant to this article was reported.

\section{ACKNOWLEDGMENTS}

The authors would like to express their appreciation for the cooperation and participation of all the children and their parents in this study.

\section{AUTHOR CONTRIBUTION}

Conceptualization: Abd-Elfattah HM, Aly SM. Methodology: Abd-Elfattah HM. Formal analysis: Aly SM. Writing - original draft: Abd-Elfattah HM. Writing - review and editing: Abd-Elfattah HM, Aly SM. Approval of final manuscript: all authors.

\section{REFERENCES}

1. Van Zelst BR, Miller MD, Russo R, Murchland S, Crotty M. Activities of daily living in children with hemiplegic cerebral palsy: a cross-sectional evaluation using the Assessment of Motor and Process Skills. Dev Med Child Neurol 2006;48:723-7.

2. Eliasson AC, Bonnier B, Krumlinde-Sundholm L. Clinical experience of constraint induced movement therapy in adolescents with hemiplegic cerebral palsy: a day camp model. Dev Med Child Neurol 2003;45:357-9.

3. Gordon AM. Development of hand motor control. In: Kalverboer AF, Gramsbergen AA, editors. Handbook of brain and behaviour in human development. Dordrecht, Netherlands: Kluwer Academic Publishers; 2001. p. 513-37. 
4. Greaves S, Imms C, Dodd K, Krumlinde-Sundholm L. Assessing bimanual performance in young children with hemiplegic cerebral palsy: a systematic review. Dev Med Child Neurol 2010;52:413-21.

5. Hoare BJ, Imms C. Upper-limb injections of botulinum toxin-A in children with cerebral palsy: a critical review of the literature and clinical implications for occupational therapists. Am J Occup Ther 2004;58:389-97.

6. Briggs AM, Greig AM, Wark JD, Fazzalari NL, Bennell KL. A review of anatomical and mechanical factors affecting vertebral body integrity. Int J Med Sci 2004;1:170-80.

7. Liemohn WP, Baumgartner TA, Gagnon LH. Measuring core stability. J Strength Cond Res 2005;19:583-6.

8. Cowley PM, Swensen TC. Development and reliability of two core stability field tests. J Strength Cond Res 2008;22:619-24.

9. Rosenblum S, Josman N. The relationship between postural control and fine manual dexterity. Phys Occup Ther Pediatr 2003;23:47-60.

10. Bohannon RW, Smith MB. Interrater reliability of a modified Ashworth scale of muscle spasticity. Phys Ther 1987;67:206-7.

11. Palisano R, Rosenbaum P, Walter S, Russell D, Wood E, Galuppi B. Development and reliability of a system to classify gross motor function in children with cerebral palsy. Dev Med Child Neurol 1997;39:214-23.

12. Jebsen RH, Taylor N, Trieschmann RB, Trotter MJ, Howard LA. An objective and standardized test of hand function. Arch Phys Med Rehabil 1969;50:311-9.

13. Taylor N, Sand PL, Jebsen RH. Evaluation of hand function in children. Arch Phys Med Rehabil 1973;54:129-35.

14. Beebe JA, Lang CE. Relationships and responsiveness of six upper extremity function tests during the first six months of recovery after stroke. J Neurol Phys Ther 2009;33:96-103.

15. Rich TL, Menk JS, Rudser KD, Feyma T, Gillick BT. Less-affected hand function in children with hemiparetic unilateral cerebral palsy: a comparison study with typically developing peers. Neurorehabil Neural Repair 2017;31:965-76.

16. Mathiowetz V, Volland G, Kashman N, Weber K. Adult norms for the Box and Block Test of manual dexterity. Am J Occup Ther 1985;39:386-91.
17. DeMatteo C, Law M, Russell D, Pollock N, Rosenbaum $\mathrm{P}$, Walter S. The reliability and validity of the Quality of Upper Extremity Skills Test. Phys Occup Ther Pediatr 1993;13:1-8.

18. Jeffreys I. Developing a progressive core stability program. Strength Cond J 2002;24:65-6.

19. Jaspers E, Desloovere K, Bruyninckx H, Klingels K, Molenaers G, Aertbelien E, et al. Three-dimensional upper limb movement characteristics in children with hemiplegic cerebral palsy and typically developing children. Res Dev Disabil 2011;32:2283-94.

20. Michelsen SI, Flachs EM, Uldall P, Eriksen EL, McManus V, Parkes J, et al. Frequency of participation of 8-12-year-old children with cerebral palsy: a multicentre cross-sectional European study. Eur J Paediatr Neurol 2009;13:165-77.

21. Lee BH, Kim YM, Jeong GC. Mediating effects of the ICF domain of function and the gross motor function measure on the ICF domains of activity, and participation in children with cerebral palsy. J Phys Ther Sci 2015;27:3059-62.

22. Kumaresan A, Mahiba JA. Effect of core muscle exercises in improving reaching activities in participants with hemiplegia. Int J Pharma Bio Sci 2016;7:B1096104.

23. Cetisli Korkmaz N, Can Akman T, Kilavuz Oren G, Bir LS. Trunk control: the essence for upper limb functionality in patients with multiple sclerosis. Mult Scler Relat Disord 2018;24:101-6.

24. McCormack DJ. The effects of keyguard use and pelvic positioning on typing speed and accuracy in a boy with cerebral palsy. Am J Occup Ther 1990;44:312-5.

25. Cordo PJ, Nashner LM. Properties of postural adjustments associated with rapid arm movements. J Neurophysiol 1982;47:287-302.

26. Silfies SP, Ebaugh D, Pontillo M, Butowicz CM. Critical review of the impact of core stability on upper extremity athletic injury and performance. Braz J Phys Ther 2015;19:360-8.

27. Behm DG, Anderson K, Curnew RS. Muscle force and activation under stable and unstable conditions. J Strength Cond Res 2002;16:416-22.

28. Ambegaonkar JP, Mettinger LM, Caswell SV, Burtt A, Cortes N. Relationships between core endurance, hip strength, and balance in collegiate female athletes. Int J Sports Phys Ther 2014;9:604-16. 
29. Kibler WB, Press J, Sciascia A. The role of core stability in athletic function. Sports Med 2006;36:189-98.

30. Fallang B, Saugstad OD, Hadders-Algra M. Goal directed reaching and postural control in supine position in healthy infants. Behav Brain Res 2000;115:9-18.

31. Miyake Y, Kobayashi R, Kelepecz D, Nakajima M. Core exercises elevate trunk stability to facilitate skilled motor behavior of the upper extremities. J Bodyw Mov
Ther 2013;17:259-65.

32. Putnam CA. Sequential motions of body segments in striking and throwing skills: descriptions and explanations. J Biomech 1993;26 Suppl 1:125-35.

33. El-Nashar H, ElWishy A, Helmy H, El-Rwainy R. Do core stability exercises improve upper limb function in chronic stroke patients? Egypt J Neurol Psychiatr Neurosurg 2019;55:38. 